\title{
UAV FOR MAPPING HISTORIC BUILDINGS: FROM 3D MODELLING TO BIM
}

\author{
E. Karachaliou, E. Georgiou, D. Psaltis, E. Stylianidis
}

Faculty of Engineering, School of Spatial Planning \& Development Aristotle University, Thessaloniki, 54124, Greece ekaracha@auth.gr, efthimios_georgiou@yahoo.gr,dimipsal@auth.gr, sstyl@auth.gr

Commission II

KEY WORDS: cultural heritage, UAV, photogrammetry, HBIM

\begin{abstract}
:
Preventive actions of cultural heritage continuously emerge in order to preserve the identity of the respective civilizations, retain its cultural significance and ensure its accessibility to present and future generations. 3D geomatics technologies along with UAV systems are widely used for documenting existing structures especially in difficult-to-access areas. In addition, Building Information Modelling (BIM) for cultural heritage gains ground towards the sustainable management, update and maintenance of the information. To this context, the current work generates a Historic Building Information Modelling (HBIM) model of the "Averof's Museum of Neohellenic art" located in Metsovo, Greece, by using UAV photogrammetry techniques and additional information derived from the architecture designs of the buildings.
\end{abstract}

\section{INTRODUCTION}

Over the last decades, innovative 3D digitisation and geomatics technologies has entered the field of cultural heritage, mainly in order to meet the needs of preservation, management and protection. The aim is to ensure that the information regarding the significant historical characteristics (shape, appearance) of a cultural heritage entity will be reserved in case of natural or other damages. In such case, the dissemination of digital representations i.e. for virtual museums purposes, uncover art forgery, as well as collect and study information that is difficult to perform it in the real object is feasible (Gomes et al., 2014).

Preventive actions of cultural heritage could be carried out either in situ or virtually, using photogrammetry and computer vision techniques. In particular, the use of UAVs is becoming very common in the field of cultural heritage and 3D reconstruction allowing fast, accurate and low-cost data acquisition especially in areas with low accessibility (Stathopoulou et al., 2015).

Moreover, a remarkable development and use of BIM technology in the field of cultural heritage has been occurred. Cultural heritage data gathered using UAVs, terrestrial laser scanners or other techniques, are transformed into parametric objects with unique standards and protocols that can be exchanged and processed from different experts (Osello and Rinaudo, 2016) in order to document any size or complex form of cultural heritage (Singh et al., 2011). In fact, when it comes to the representation and management of existing structures these models are commonly described with the term "as-built" BIM.

The development of an "as-built" BIM requires the data acquisition of the current state of the relevant structure (Macher et al., 2017), the geometrical modelling of the objects, the attribution of categories and material properties to the objects and the creation of relations between them (Hichri et al., 2013). In this case, the use of 3D point cloud data of the built environment, providing the real capture of the field conditions, serves as a solution to enhance 3D BIM applications (Qu and Sun, 2015).

This paper will describe in detail the activities carried out and the methodology followed to document an existing structure of high cultural value and generate its digital 3D model by combining novel techniques as UAV photogrammetry and BIM and by leveraging additional information derived by common representation methods such as architectural designs. The results will contribute to a deeper understanding of how challenging methods of data acquisition and digital representation can go hand in hand and interconnect towards an accurate, simple and cost-effective documentation, storage and study of an existing building unit.

\section{RELATED WORK}

Significant research has been carried out both in the field of UAV photogrammetry for cultural heritage as well as in the HBIM development for the cultural heritage documentation and preservation.

In 2009, Murphy, McGovern and Pavia realized an extensive review on HBIM and its stage of development. Later in 2013 they indicated that HBIM has huge potential for use in the conservation of historic structures and environments, as well as presented the methodology for the development of a library consisting of interactive parametric objects based on historic architectural data. Furthermore, Dore and Murphy in 2012 presented a two-stage approach for digitally recording cultural heritage sites, which involved the integration of HBIM with 3DGIS by using CityGML.

Moreover, Oreni et al. in 2013 hold an extensive research on the possibility to advance from 3D content models to HBIM in order to support broader heritage preservation activities and information sharing, as well as investigating the potential of defining of an HBIM targeted library (vault and wooden bean floor case studies analysis).

In addition, a case study of management of cultural heritage through the development of HBIM was carried out in Spain by Nieto et al. in 2015, focusing on flooring and wall tilling of a historic building using laser scanning and photogrammetric techniques. 
Recently, in 2018, two noticeable researches were presented. The first refers to the implementation of an HBIM system for the Parma cathedral (Bruno and Roncella, 2018), aimed at its maintenance, conservation and restoration. Topographic, laser scanning and photogrammetric surveys were combined and fed in the 3D modelling and BIM creation using Revit software. The preliminary results showed that HBIM is very promising solution for more coordinated and efficient management and preservation, as well as that the available acquisition techniques are well established leading to high precisions. However, there is room for improvement in in terms of costs, training and processing times. The second focuses on the development of a prototype HBIM schema for Chinese built heritage building, in Taiwan (Lu et al., 2018).

\section{CASE STUDY - THE AVEROF'S MUSEUM}

For the purposes of the current work, the case of the Averof's Museum of Neohellenic art was selected. The Averof Museum is located in the traditional village of Metsovo, Ioannina, Greece (Fig.1). Metsovo is built in very steep slope in the mountainous area of the region Epirus of Greece since the 15th century. It has been characterized as a "traditional settlement" since 1978 being known especially for its local architecture where the basic building materials are wood and stone.

The museum was inaugurated in 1988 representing the traditional architecture of Metsovo. The Averof's Museum was undergone maintenance and restoration works in order to be transformed in a gallery without altering the exterior facade and its traditional character (Fig.2).

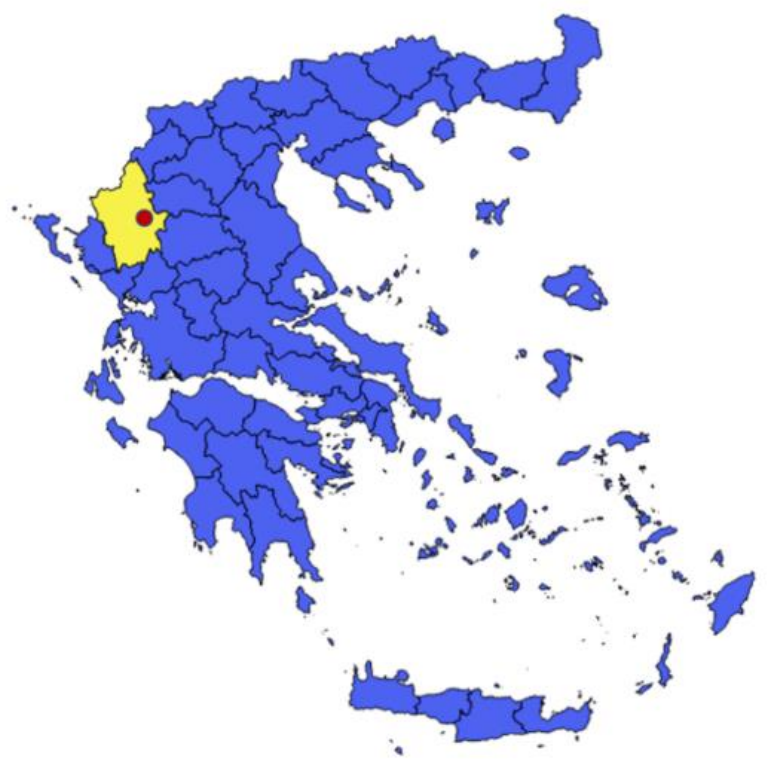

Figure 1: Metsovo village (red), Epirus region (yellow) (geodata.gov.gr, 2018)

Today, the museum hosts more than 200 works of art of Greek artists from the 19th and 20th centuries and attracts about 20.000 visitors a year. It's significant historical and cultural value, especially for the region of Epirus, confirms the need of its preservation through time.
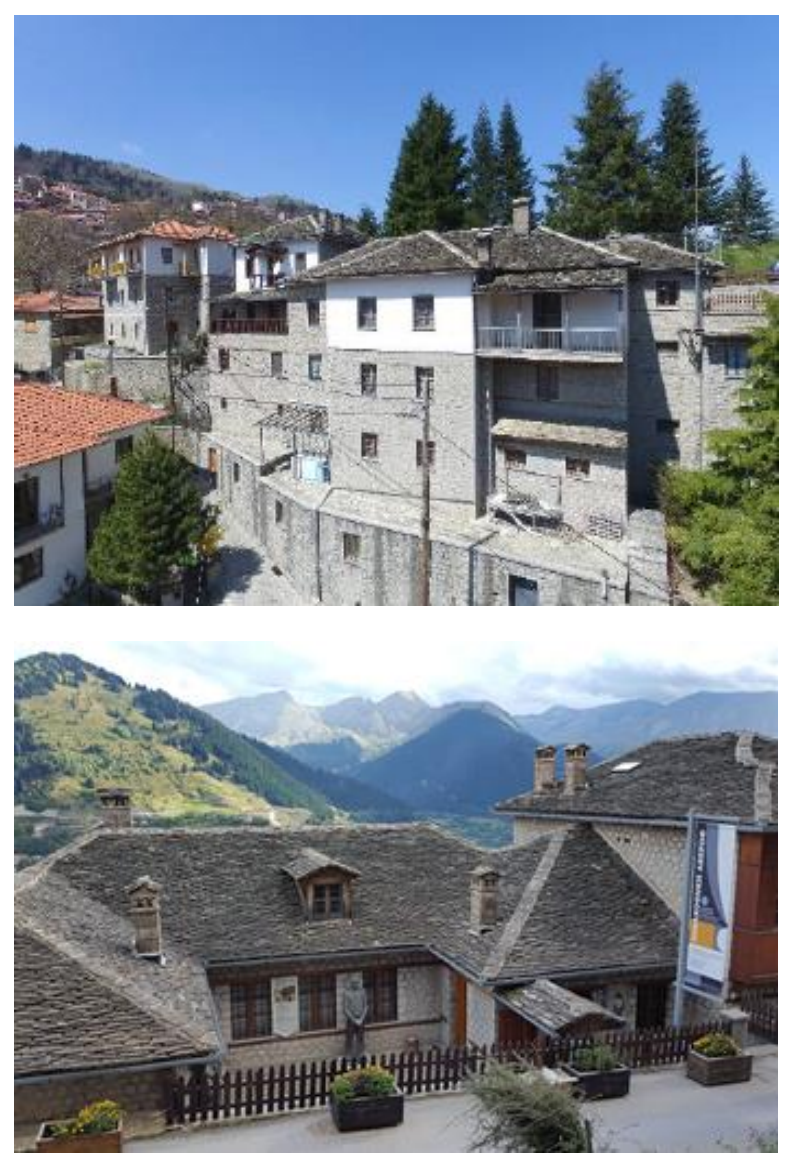

Figure 2: Averof's Museum of Neohellenic art in Metsovo, Greece.

\section{WORKFLOW}

Figure 3 presents the workflow followed for the HBIM generation of the heritage building. Considering the low accessibility to the area a UAV data acquisition was implemented. The captured data along with the available architectural designs underwent through photogrammetric processing aiming to generate orthoimages of a high accuracy.

The orthoimages of the (exterior) facades of the building along with the architectural designs and on site measurements were then used for the development of the BIM system of Averof's Museum.

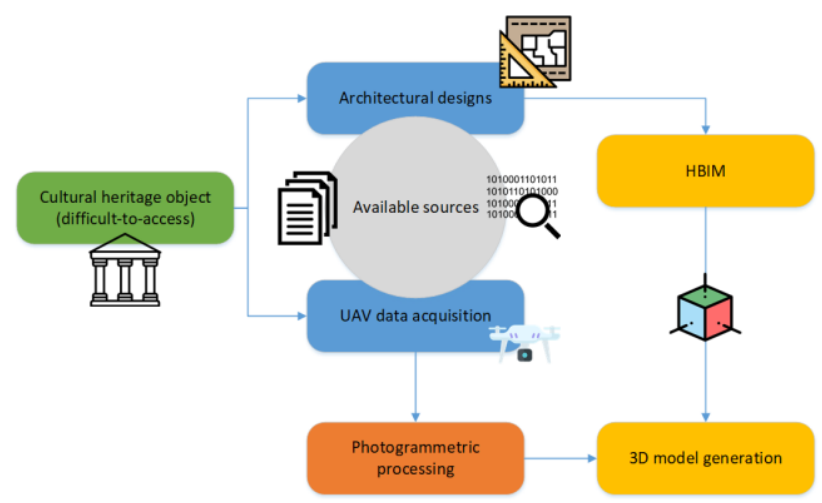

Figure 3: Workflow of the BIM generation of Averof's Museum, Metsovo, Greece 


\section{UAV PHOTOGRAMMETRY}

\subsection{Data Acquisition of the building facades}

Cultural heritage documentation is one of the major sectors where UAV systems find a wide application, mainly due to their low cost, flexibility, availability and readiness to perform (Caprioli et al., 2015). In addition, drawing on UAVs' ability to operate in difficult-to-access locations, they turn out to be the best solution for surveillance and data acquisition in otherwise inaccessible areas or structures.

Likewise, Averof's Museum location made inevitable the ground-based data collection. Due to the mountainous location of the building and the low accessibility of the area, UAV data acquisition was the optimum choice in terms of cost, time and coverage in order to acquire the entire structure of the building. Thus, in April 2017 a DJI Phantom 3 Professional, equipped with a 12Megapixel camera, was used in order to collect images of the building facades. The flight was planned by using the online platform www.healthydrones.com/airdata and performed in 3 strips ( 2 vertical \& 1 oblique).

A total of 144 images (Fig. 4) were captured with an overlap of $80 \%$ between the first and the second image and $35 \%$ overlap between the first and the third (for each triple of photos). However, obstacles such as electricity cables rendered the acquisition of the west side of the building difficult resulting in a distortion of that facade in the final orthoimages.

In addition, apart from the digital images, the museum kindly provided the project-team with the architectural designs of the exterior and interior in order to extract information regarding its dimensions.

\subsection{Orthoimages generation}

The data collected were processed in Agisoft Photoscan photogrammetry software. A masking procedure was applied on the images aiming to exclude the background throughout the photo alignment process and produce a less noisy point cloud. Therefore, a textured mesh was produced (Fig.5) and the orthoimages of the buildings' (exterior) facades were generated (Fig.6).

\section{DATA FUSION FOR CREATING BIM MODEL}

The concept of modelling building information has been related to widely used terms (i.e., Asset Lifecycle Information System, Building Product Models, Integrated Design Systems, Integrated Project Delivery, etc.) (Succar, 2009) and has found application predominantly in the AEC industry.

BIM models are practically useful for any kind of lifecycle management of a building or other structure and provide many benefits regarding: the $3 \mathrm{D}$ visualization; the fabrication; the cost estimation; the code reviews; the construction sequencing; the conflict, interference, and collision detection; the forensic analysis; the facilities management; etc. (Azhar, 2011).

Nevertheless, BIM models could be developed to support the building maintenance and deconstruction, rather than only facilitating the new construction of a building. The latest trends/challenges in the field of BIM for existing buildings follow topics such as the automation of data collection and BIM development (without a previously developed BIM model), the update and maintenance of information in BIM, and the management and modelling of unknown data, objects, and relations in existing buildings (Volk et al., 2014). This advancement in the past decade, allowed for the remarkable development and use of BIM technology in the field of cultural heritage.
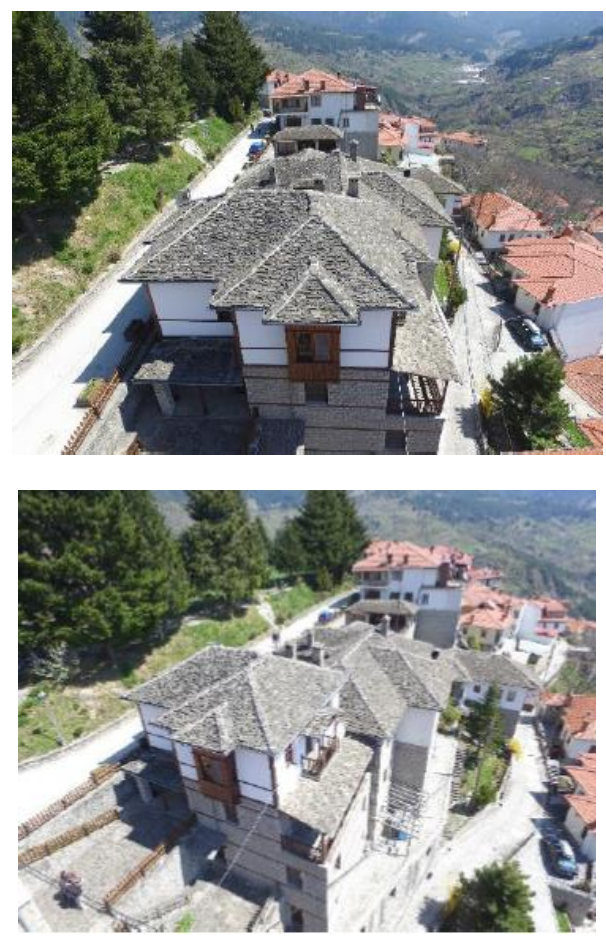

Figure 4: Aerial images of the Averof Museum captured with DJI Phantom 3 Professional

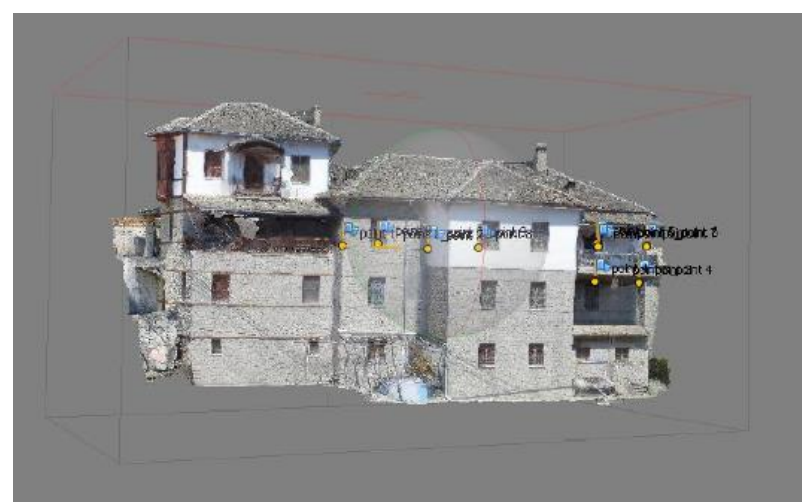

Figure 5: Textured mesh produced in Agisoft Photoscan

Historic Building Information Modelling (HBIM) is latter-day solution for generating parametric objects of architectural structures (mapped onto a point cloud or image-based survey) by using historic data (Murphy et al., 2013). Although BIM environments were initially structured to generate and manage from zero parametric geometries and create objects using existing libraries of shapes and conditions, however the HBIM approach was developed, referring to the process by which the architectural elements are collected; e.g. using a terrestrial laser scanner, and produced photogrammetric survey data are converted into parametric objects (Dore and Murphy, 2012). In this way, it is possible to document and manage any size or complex form of a cultural heritage object (Singh et al., 2011). Moreover, the BIM approach in the cultural heritage field allows the generation of a parametric model with specific standards and protocols that can be exchanged and processed from different professionals in order to be used for various use-cases (Osello and Rinaudo, 2016). 


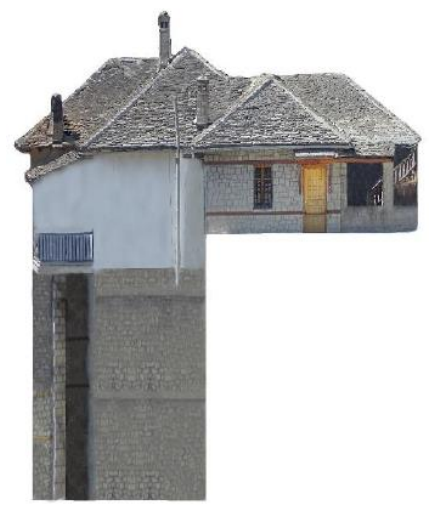

Eastern facade

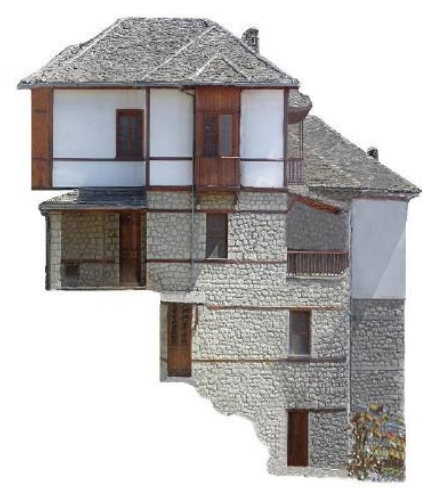

Western facade

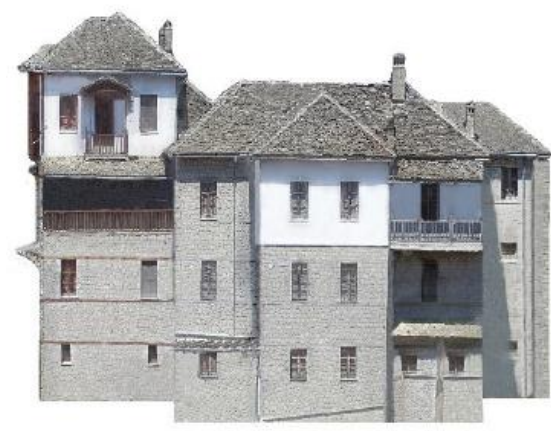

South facade

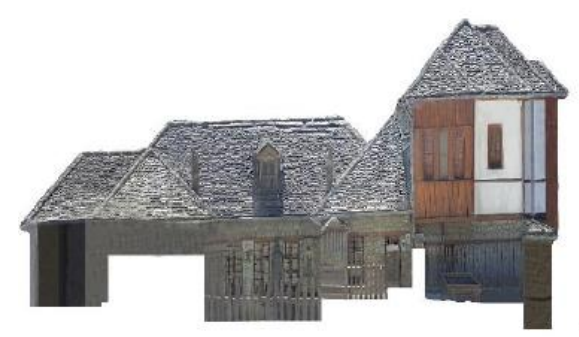

North facade

Figure 6: Orthoimages of the building facades

Recent experimentation in the field (Bruno and Roncella, 2018) indicates that even though there is lot to overcome in terms of costs, training and processing times, the utilization of "HBIM in the cultural heritage field is a good solution and a potential for more coordinated and efficient management and preservation".
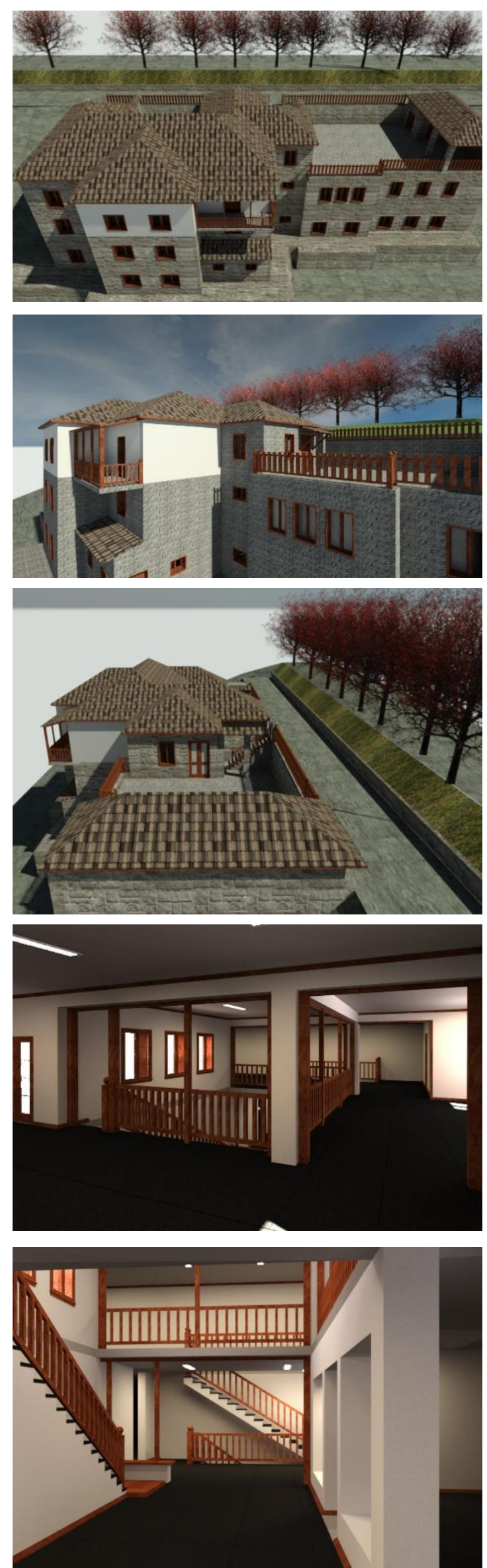

Figure 7: Snapshots from the BIM model 
In the current work, an HBIM model of the Averof's museum was generated utilizing:

a) the orthoimages of the facades produced with UAV photogrammetry processes,

b) the architectural designs of both the exterior and the interior,

c) on-site measurements of the interior places of the building.

Since there is no currently available any complete open-source software for BIM/HBIM (Logothetis et al., 2017), the development of the HBIM model was carried out using the REVIT Autodesk platform.

The final result (Fig. 7) consists of a complete, true and accurate 3D model of the cultural heritage Averof's Museum building.

\section{CONCLUSIONS}

Cultural heritage (tangible or intangible) needs preservation as for ensuring that its significance will be readily accessible to future generations. Nowadays, photogrammetry, laser scanning techniques and geomatic technologies are used in order to collect data and information of a cultural heritage entity and to produce accurate $3 \mathrm{D}$ digital representations to be used for conservation purposes.

Gradually, the use of UAVs has become popular in recent years as technology advances and pricing have made them more accessible to individual users. However, the use of UAV evolves challenging issues, especially for the flight permits, safety and security.

In addition, the last decade considerable research has been carried out focusing on the potential of applying BIM systems to support cultural heritage preservation activities.

The current case study aimed at the digital representation of a heritage building towards its cultural preservation through time. The processing workflow that was followed, combined:

d) UAV photogrammetry for recording the building facades

e) Existing drawings of the interior and exterior of the building

f) Data fusion for creating a BIM model.

The high accuracy documentation generated from the BIM model can be used for future renovation or expansion of the Museum, as well as for educational activities.

\section{ACKNOWLEDGEMENTS}

The authors would like to acknowledge the Evangelos AveroffTossizza Foundation for providing the architectural designs of the Averof's Museum building.

\section{REFERENCES}

CGAL, 2018. Computational Geometry Algorithms Library, http://www.cgal.org (Last accessed on July 2018).

Azhar, S., 2011. Building Information Modeling (BIM): Trends, Benefits, Risks, and Challenges for the AEC Industry.
Leadership and Management in Engineering, Vol. 11, pp. 241252.

Bruno, N. and Roncella, R., 2018. A restoration oriented hbim system for cultural heritage documentation: the case study of parma cathedral, The International Archives of Photogrammetry, Remote Sensing and Spatial Information Science, XLII-2, pp. 171-178.

Caprioli, M., Mancini, F., Mazzone, F., Scarano, M. and Trizzino, R., 2015. UAV Surveys for Representing and Document the Cultural Heritage. Proceedings of XIII International Forum Le Vie dei Mercanti Heritage and Technology, Aversa and Capri, 11-13 June.

Dore, C. and Murphy, M., 2012. Integration of Historic Building Information Modeling and 3D GIS for Recording and Managing Cultural Heritage Sites, 18th International Conference on Virtual Systems and Multimedia: "Virtual Systems in the Information Society", 2-5 September, 2012, Milan, Italy, pp. 369-376.

Gomes, L., Regina Pereira Bellon, O. and Silva, L., 2014. 3D reconstruction methods for digital preservation of cultural heritage: A survey. Pattern Recognition Letters, Vol. 50, pp. 314.

Hichri, N., Stefani, C., Luca, L.D.E., Veron, P. and Hamon, G., 2013. From point cloud to BIM: a survey of existing approaches. Proceedings of the XXIV International CIPA Symposium.

Logothetis, S., Karachaliou, E. and Stylianidis, S., 2017. From OSS CAD to Bim for Cultural Heritage Digital Representation. The International Archives of Photogrammetry, Remote Sensing and Spatial Information Science, Vol. XLII-2/W3, pp. 439-445.

Lu, Y., C., Shih, T., Y., and Yen, Y., N., 2018. Research on historic bim of built heritage in taiwan - a case study of huangxi academy, The International Archives of Photogrammetry, Remote Sensing and Spatial Information Science, Vol. XLII-2, pp. 615-622.

Macher, H., Landes, T. and Grussenmeyer, P., 2017. From Point Clouds to Building Information Models: 3D Semi-Automatic Reconstruction of Indoors of Existing Buildings. Applied Sciences, Vol. 7.

Murphy, M., McGovern, E. and Pavia, S., 2009. Historic building information modelling (HBIM). Structural Survey, Vol. 27(4), pp. 311-327.

Murphy, M., McGovern, E. and Pavia, S., 2013. Historic Building Information Modelling - Adding intelligence to laser and image based surveys of European classical architecture. ISPRS Journal of Photogrammetry and Remote Sensing, Vol. 76, pp. 89-102.

Nieto, J., E., Moyano, J., J., Delgado, F., R., and García, D., A., 2016. Management of built heritage via HBIM Project: A case of study of flooring and tiling. Virtual Archaeol. Rev., Vol. 7, pp. $1-12$.

Oreni, D., Brumana, R., Georgopoulos, A., and Cuca, B., 2014. HBIM Library Objects for Conservation Heritage. The Int. J. of Heritage in the Digital Era, Vol. 3(2). 
Osello, A. and Rinaudo, F., 2016. Cultural Heritage Management Tools: The Role of GIS and BIM. 3D Recording, Documentation and Management of Cultural Heritage.

Qu, T. and Sun W., 2015. Usage of 3D Point Cloud Data in BIM (Building Information Modelling): Current Applications and Challenges. Journal of Civil Engineering and Architecture, Vol. 9, pp. 1269-1278.

Singh, V., Gu, N. and Wang, X., 2011. A theoretical framework of a BIM-based multi-disciplinary collaboration platform. Automation in Construction, Vol. 20(2), pp. 134-144.

Stathopoulou, E.K., Georgopoulos, A., Panagiotopoulos, G. and Kaliampakos, D., 2015. Crowdsourcing lost cultural heritage. ISPRS Annals of the Photogrammetry, Remote Sensing and Spatial Information Sciences, Vol. II-5/W3.

Succar, B., 2009. Building information modelling framework: A research and delivery foundation for industry stakeholders. Automation in Construction, Vol. 18(3), pp. 357-375.

Volk, R., Stengel, J. and Schultmann, F., 2014. Building Information Modeling (BIM) for existing buildings-Literature review and future needs. Automation in Construction, Vol. 38, pp. 109-127. 